\title{
O drama e a alegria da tradução: Gwendolyn Brooks versando a vida em três poemas ${ }^{1}$
}

\author{
Lauro Maia Amorim²
}

\begin{abstract}
Resumo: Propõe-se, com este trabalho, a tradução comentada de três poemas da premiada poeta afro-americana Gwendolyn Brooks. Discutem-se as diferentes dimensões interpretativas que seus poemas sugerem e suas implicações para as estratégias de tradução adotadas para a sua recriação em língua portuguesa.
\end{abstract}

Palavras-chave: tradução; poesia; literatura afro-americana; Gwendolyn Brooks

\section{Introdução}

Gwendolyn Brooks (1917-2000) é considerada uma das maiores poetas da literatura norte-americana, tendo dado uma contribuição singular e inestimável à própria história da literatura afro-americana.

Embora tenha nascido em Topeka, Kansas, Brooks é particularmente lembrada como uma chicagoense, tendo vivido a maior parte de sua vida em Chicago. Seu primeiro livro de poesias, A Street in Bronzeville, publicado em 1945, recebeu imediata aclamação crítica. Tornou-se, em 1950, a primeira afro-americana a ganhar o prêmio Pulitzer de Poesia, pela obra Annie Allen (1949).

Além de ter sido contemplada, ao longo da vida, com inúmeros prêmios, Gwendolyn Brooks foi condecorada, em 1990, com o título de Doutora em

1 Gostaria de manifestar meus agradecimentos aos pesquisadores-tradutores John Milton (USP), Paulo Henriques Britto (PUC-RJ) e Marcos Bagno (UnB) por seus valiosos comentários acerca das traduções.

2 Departamento de Estudos Linguísticos e Literários - Universidade Estadual Paulista "Júlio de Mesquita Filho" - Campus de São José do Rio Preto, São Paulo. 
Humane Letters. Em 1967, na Fisk University (universidade estadunidense historicamente frequentada por alunos predominantemente negros), a poeta participou do Segundo Congresso de Escritores Negros, onde teve a oportunidade de conhecer artistas e ativistas do movimento negro político-estético Black. Arts Movement, como Amiri Baraka, Larry Neal, entre outros. Esse encontro exerceu uma influência importante na sua produção poética posterior. Estudiosos, no entanto, reconhecem que a crítica social nunca deixou de estar presente em seus primeiros poemas, o que pode ser atestado nas traduções aqui apresentadas.

Em uma entrevista, Brooks chegou a afirmar que a matéria de sua poesia era a vida cotidiana, observada de sua kitchenette. Como bem destaca Gates e McKay (2004), embora também tenha cultivado o verso livre, a poesia de Brooks sempre impressionou os leitores pelo seu "domínio absoluto da rima e da métrica; pelo emprego sofisticado da ironia, tanto formal quanto temática, como em seu poema 'We Real Cool' [aqui traduzido], e por sua delicada e não menos impressionante tradução de eventos públicos em detalhes poéticos memoráveis" (p. 1624).

Como veremos a seguir, três poemas nos revelam três olhares que se caracterizam pela ironia, pela transgressão, e pelo que há de mais pungente na dor perante aquilo que não se esquece: do eu lírico trágico-jocoso de "We Real Cool"; passando pela transgressão vislumbrada por uma menina em "a song in the front yard", até chegar às memórias de uma mãe solitária em "the mother", Gwendolyn Brooks nos surpreende com sua delicadeza e sua lucidez poética, especialmente ao tratar de temas e situações envolvendo as ironias que cercam o drama (e a alegria) de viver. 


\title{
Poemas traduzidos e comentados
}

\section{We Real Cool: “A Gente é da Hora” e "A Gente é Legal”}

\author{
Versão "A Gente é da Hora"
}

We Real Cool ${ }^{3}$

The Pool Players.

Seven at the Golden Shovel.

We real cool. We

Left school. We

Lurk late. We

Strike straight. We

Sing sin. We

Thin gin. We

Jazz June. We

Die soon.

\section{A Gente é da Hora}

Jogadores de Sinuca.

Sete no Taco de Ouro.

A gente é da hora. A gente

Largou a escola. A gente

Embala na balada. A gente

Ataca na tacada. A gente

Xinga sim. A gente

Ginga gim. A gente

Funkeia fevereiro. A gente

Morre bem cedo.

Este é um dos poemas mais conhecidos de Gwendolyn Brooks. Caracterizado pela forma compacta, especialmente porque todas as palavras são monossilábicas, o poema contém apenas três palavras por verso (à exceção do primeiro), cada um, a partir do segundo, se iniciando com um enjambement. Tem a força da oralidade aliada ao labor poético caracterizado por aliterações e assonâncias que conferem acentuada musicalidade ao poema ${ }^{4}$. Ele promove a reflexão em torno da juventude negra, expressa na reunião de sete jovens em torno de uma mesa de sinuca. O poema contrasta a liberdade buscada e praticada pelos jovens, que questionam a viabilidade da escola em suas vidas ("We" "Left school"), celebran

3 Originalmente publicado em The Bean Eaters (1960).

$4 \mathrm{Na}$ internet há uma gravação muito famosa desse poema sendo recitado por Gwendolyn Brooks e que demonstra sua musicalidade, especialmente quando a poeta chega ao último verso, finalizando-o com uma nota musical. 
do a diversão ("We"/“Sing sin./"We"/“Thin gin") e a ousadia como fontes de liberdade contra o ensinamento de preceitos morais. O poema também reserva certas ambiguidades, como "we strike straight", que pode ser lido tanto como "nossa tacada - na sinuca - é certeira" mas, também, como "a gente ataca/bate pra valer", ou seja, a dimensão lúdica do jogo se mistura à violência. Além disso, "We" / "Jazz June" sugere mais de um sentido: diversão aliada à música jazzística, especialmente em "junho", mês do verão e da diversão nos Estados Unidos; mas “jazz” também pode ser sinônimo de fazer sexo. Ressalta-se, ainda, a importância de "We" ao longo do poema: ao ser proferido ao final do verso, a dimensão coletiva de "We" ganha um destaque gráfico, produzindo-se uma reverberação significativa ao longo de todo o poema. A afirmação da liberdade se contrasta, no final, com o reconhecimento da morte prematura pelo eu lírico coletivo.

Foram propostas duas traduções para o mesmo poema. A primeira versão, intitulada "A Gente é da Hora", tem um caráter mais experimental no que diz respeito à criação de aliterações e assonâncias que pudessem expressar, de maneira recíproca, a dimensão estética que corporifica sentidos e sons no poema original. Assim, por exemplo, "embala na balada" procura, ao mesmo tempo, refletir o sentido de diversão às altas horas da noite e as consoantes laterais em "lurk late", contribuindo também, com o verso seguinte, na construção da rima: "ataca na tacada" - uma opção que busca lidar com a ambiguidade sonora de "strike straight", podendo, assim, revelar a "tacada" certeira na sinuca, mas, também, o sentido de violência sugerido em "strike".

Embora, semanticamente, os versos "Xinga sim/Ginga gim" apontem para deslocamentos mais acentuados na tradução (especialmente porque o primeiro verso não apresenta, senão de maneira oblíqua, o sentido de "pecado" do verso em inglês) eles procuram representar as aliterações ("Sing sin") e assonâncias ("Sing sin"/"Thin gin") dos respectivos originais, aproximando-se mais, portanto, do aspecto formal e rítmico dos versos em inglês. Essa opção, porém, consegue manter o necessário grau de coloquialismo que o contexto do poema exige.

Além disso, recorreu-se a uma tradução mais domesticadora de "Jazz June", adaptando tanto o referencial musical ("Funkeia") quanto a referência temporal ("fevereiro"). Certamente essa opção permite uma maior adequação ao contexto brasileiro de enunciação, uma vez que o jazz, como gênero musical, é muito menos popular no Brasil, do que nos Estados Unidos (e mesmo lá, atualmente, tem menos penetração entre os mais jovens, em comparação a gêneros como rap ou hip-hop, do que nos anos 60, quando o poema foi concebido). Vale ressaltar que a associação entre "funkeia" e "fevereiro" sugere (tanto quanto "Jazz", em 
seu sentido sexual), a imagem implícita do carnaval, do verão e a exploração da sensualidade, tão presente nos populares bailes funks.

Um problema de difícil solução é o fato de que, no poema em inglês, as palavras monossilábicas tornam o texto mais compacto, especialmente do ponto de vista gráfico, o que não se realizou na tradução, já que a exigência de preposições e artigos acabam, de certa forma, por tornar o poema mais longo, ainda que um certo grau de coloquialidade, em português, tenha sido preservado. Uma possível solução seria recorrer ao pronome "nós", em vez de "a gente", especialmente com uma conjugação não padrão: "nós ataca na tacada", "nós embala na balada", etc. Essa opção teria a vantagem de tornar o poema mais curto em português. Contudo, acaba por gerar outra questão: com exceção do título ("We Real Cool”), um possível exemplo do inglês afro-americano vernacular (ou "Black English"), o poema não apresenta construções linguísticas não padrão, não suscitando, assim, formas estigmatizadas. ${ }^{5}$

Embora essas formas não padrão possam ser opções legítimas de tradução, até porque são produções linguísticas reais, faladas por grupos sociais com menor escolaridade, optamos por não utilizá-las na medida em que Gwendolyn Brooks, ao longo do poema, não recorreu a formas estigmatizadas, mas a combinações lexicais que não deixam de expressar coloquialidade. Vejamos, agora, a segunda versão proposta:

5 Isso não significa, porém, que todas as formas linguísticas consideradas não padrão sejam, necessariamente, estigmatizadas: como demonstram as pesquisas sociolinguísticas, em contextos de fala informal, o emprego de pronome sujeito em posição clítica (como "Eu encontrei ela ontem"), por exemplo, é muito mais recorrente que a forma considerada padrão ("Eu a encontrei ontem"), mesmo entre falantes escolarizados, o que demonstra que seu uso não enseja reações de estigmatização como no caso de outras formas linguísticas não padrão, como aquelas que envolvem o fenômeno do rotacismo ("brusa", "Cráudia" ou "Framengo"). 


\section{Versão “A Gente é Legal”}

We Real Cool

The Pool Players.

Seven at the Golden Shovel.

We real cool. We

Left school. We

Lurk late. We

Strike straight. We

Sing sin. We

Thin gin. We

Jazz June. We

Die soon.

\section{A Gente é Legal}

Jogadores de Sinuca.

Sete no Taco de Ouro.

A gente é legal. A gente

Largou o colegial. A gente

Manda na madruga. A gente

Acerta na sinuca. A gente

Foge de igreja. A gente

Segue a cerveja. A gente

Samba à beça. A gente

Morre depressa.

A segunda versão busca também recriar os efeitos sonoros do plano do significante, com aliterações, assonâncias, além das rimas internas e externas. Por outro lado, é uma versão ligeiramente mais coloquial que a anterior, até porque se vale de construções linguísticas menos inusitadas que a primeira tradução (como, por exemplo, com "Ginga gim" ou "Funkeia fevereiro", ou mesmo com "embala na balada" / "ataca na tacada" - que emprestam ao poema um ritmo mais sincopado). Obviamente, a segunda versão também poderia ser facilmente musicada, no entanto, seria uma versão musical com frases mais próximas do discurso falado.

$\mathrm{Na}$ terceira estrofe, retomamos, de forma menos oblíqua, o verso "Sing sin", na medida em que "a gente foge de igreja" sugere, também, a percepção, baseada no senso comum, de que isso seria certamente uma forma de "pecado" (especialmente porque eles "fogem de igreja" para beber e se divertir). A opção por cerveja, além de contribuir para a manutenção da rima, é uma bebida muito mais popular no Brasil que o gim, o que ajuda a produzir uma imagem aparentemente mais clara do que seria a realidade vivida por jovens negros no Brasil.

É claro que devemos ponderar sobre outros aspectos: pode-se dizer que certamente a cerveja também é muito mais popular que o gim nos Estados Unidos, e esta não é necessariamente tão cara que não possa ser consumida - como realmente é - por pessoas de menor poder aquisitivo no Brasil. Ocorre que "gin" 
rima perfeitamente com “sin" (são verdadeiros “minimal pairs"), sendo uma opção da autora muito mais motivada pela dimensão estética, do que pela constatação da maior ou menor popularidade da bebida nos Estados Unidos. Isso não impede, certamente, que o tradutor vislumbre uma situação de maior proximidade com a realidade vivida na cultura de recepção da tradução. Daí a justificativa para uma segunda versão.

Os dois últimos versos, em consonância com o discurso falado, trazem à baila, a imagem do samba (com suas respectivas aliterações e assonâncias: "S $\mathbf{a}$ m$\mathbf{b} a$ à beça") e o pressuposto de que o verso "Jazz June", em nossa interpretação, focaliza, em grande medida, o sentido de alegria, musicalidade e diversão. A vantagem do último verso é ser conciso, valendo-se apenas de duas palavras: "Morre depressa" ("Die soon"). 


\section{A song in the front yard: uma canção no jardim da frente}

\section{a song in the front yard ${ }^{6}$}

I've stayed in the front yard all my life.

I want a peek at the back

Where it's rough and untended and Thungry weed grows.

A girl gets sick of a rose.

I want to go in the back yard now And maybe down the alley, To where the charity children play. I want a good time today.

They do some wonderful things. They have some wonderful fun. My mother sneers, but I say it's fine How they don't have to go in at [quarter to nine.

My mother, she tells me that Johnnie

Mae

Will grow up to be a bad woman.

That George'll be taken to Jail soon [or late

(On account of last winter he sold [our back gate).

But I say it's fine. Honest, I do.

And I'd like to be a bad woman, too,

And wear the brave stockings of

[night-black lace

And strut down the streets with paint [on my face

\section{uma canção no jardim da frente}

Fiquei no jardim da frente a vida toda. Agora quero poder espiar o fundo

Malcuidado, onde a erva daninha [cresce sequiosa.

Uma garota se entedia com uma rosa.

Quero ir para o quintal agora

E quem sabe poder entrar nesse beco, Onde brinca a criançada carente.

Hoje quero me divertir realmente.

Elas fazem umas coisas maravilhosas.

Maravilha de folia elas têm pra dar.

Mamãe desdenha, mas tudo bem

E horário para entrar, como é que

[elas não têm?

Minha mãe, ela fala que a Johnnie Mae

Vai se tornar uma mulher má.

Que o George cedo ou tarde vai pra

(No inverno vendeu nossa porta [cadeia

pra lareira).

Mas, sinceramente, eu digo tudo bem.

Bem que eu gostaria de ser uma [mulher má, também,

E vestir uma cinta-liga preta de renda

E desfilar pelas ruas com a minha [ousada

[cara pintada

6 Originalmente publicado em A Street in Bronzeville (1945). 
O poema "a song in the front yard" é um dos que, ao lado de "the mother" (aqui traduzido), compõem o livro A Street in Bronzeville, primeira obra poética publicada por Gwendolyn Brooks, em 1945. A obra reúne poemas que retratam a vida dos moradores de um bairro de Chicago. $\mathrm{O}$ foco do poema recai sobre o olhar de uma garota, cujo eu lírico se vê diante do desejo de romper com as amarras do cotidiano e com as imposições de uma vida cercada de regras. O poema, de certa forma, anuncia esse desejo, já nos dois primeiros versos ("I've stayed in the front yard all my life"/ "I want a peek at the back"), porém, ao longo do poema, a garota observa, atenta, a beleza de uma vida mais livre à sua volta, tendo que, aparentemente, aceitar o olhar judicativo e conservador de sua mãe. Mas, como leitores, somos surpreendidos com o desfecho do poema (embora o eu lírico, aos poucos, vá nos preparando para o desfecho ao afirmar repetidamente "it's fine" após cada observação de sua mãe): mais do que simplesmente ser livre, ela quer transgredir esse olhar limitador da sociedade, representado pela mãe, vestindo-se como, e mais do que isso, tornando-se, ela mesma, “a bad woman”. É um poema de contrastes: revela a garota comportada e protegida do mundo, mas também traz à tona a condição social das crianças carentes; a imagem do morador de bairro que furta a porta dos fundos para vendê-la no inverno; e, é claro, a própria imagem da familia negra (geralmente protestante) que segue, à risca, valores e comportamentos de acordo com a moral estrita como forma de responder, muitas vezes, à própria imagem negativa que a sociedade branca atribui à comunidade negra (como a sua suposta hipersexualidade, a violência, entre outros aspectos negativos). Por outro lado, o poema fala de condições profundamente universais quando toca na questão do desejo reprimido, da busca pela liberdade e da afirmação da individualidade perante os anseios e pressões da sociedade. Deve-se ressaltar, também, o vínculo do poema com a dimensão de gênero. Isso não o torna, porém, menos universal, na medida em que se aplica à marginalização das mulheres em praticamente todas as sociedades: a repressão do seu desejo bem como da sua individualidade.

Do ponto de vista formal, é um poema complexo especialmente porque se vale de uma regularidade variável, já que, em certas estrofes, há versos que compartilham o mesmo número de sílabas poéticas ao lado de outros cujo número é diferente. Pode-se observar, abaixo, no poema original e no traduzido, o número de sílabas em cada verso: 
I've stayed in the front yard all my life. 9 I want a peek at the back 7

Where it's rough and untended and hungry weed grows. 12

A girl gets sick of a rose. 7

I want to go in the back yard now 9

And maybe down the alley, 7

To where the charity children play. 9

I want a good time today. 7

They do some wonderful things. 7 They have some wonderful fun. 7 My mother sneers, but I say it's fine 9 How they don't have to go in at quarter [to nine. 12 My mother, she tells me that Johnnie [Mae 10

Will grow up to be a bad woman. 9 That George'll be taken to Jail soon [or late 10

(On account of last winte $r$ he sold [our back gate). 12

But I say it's fine. Honest, I do. 9

And I'd like to be a bad [woman, too, 10

And wear the brave stockings of [night-black lace 10 And strut down the streets with paint [on my face 10
Fiquei no jardim da frente a vida toda. 11 Agora quero poder espiar o fundo 12

Malcuidado, onde a erva daninha cresce [sequiosa. 15

Uma garota se entedia com uma rosa. 12

Quero ir para o quintal agora 9

$\mathrm{E}$ quem sabe poder entrar nesse beco, 11 Onde brinca a criançada carente. 9 Hoje quero me divertir realmente. 11

Elas fazem umas coisas maravilhosas. 12 Maravilha de folia elas têm pra dar. 12 Mamãe desdenha, mas tudo bem 9

E horário para entrar, como é que elas

Minha mãe, ela fala que a Johnnie [não têm? 12 [Mae 11

Vai se tornar uma mulher má. 9

Que o George cedo ou tarde vai

No inverno vendeu nossa porta [pra cadeia 11 [pra lareira). 12

Mas, sinceramente, eu digo tudo bem. 11

Bem que eu gostaria de ser uma [mulher má, 15 [também.

E vestir uma cinta-liga preta de [renda ousada 15

E desfilar pelas ruas com a minha

[cara pintada 15

Manter exatamente o mesmo número de sílabas do original na tradução é uma tarefa complexa, senão impossível em muitos casos, já que o inglês conta com um número muito maior e variado de palavras monossilábicas que contribuem para que o verso tenha um número reduzido de sílabas.

O que se buscou, na tradução, foi recriar versos que, de algum modo, pudessem expressar uma regularidade semelhante, ainda que, comparativamente ao original, a tradução tenha se valido de um número de sílabas diferente. 
Assim, por exemplo, enquanto na primeira estrofe em inglês, somente os versos 2 e 4 têm o mesmo número de sílabas (7 sílabas), no poema traduzido, os versos 2 e 4 correspondentes também dispõem de um mesmo número de sílabas (12 sílabas).

Essa correspondência foi mantida ao longo do poema, o que exigiu, naturalmente, transformações aliadas à necessidade de criação de rimas finais. Essas transformações, no entanto, não impedem uma leitura que se queira recíproca em relação ao poema inglês, de modo que se buscou também, recriar, em português, um texto tanto mais próximo quanto possível da oralidade, o que pode ser observado, por exemplo, em palavras como "criançada", em frases como "Minha mãe, ela fala que...", "Bem que eu gostaria de...", e no verso como "Maravilha de folia elas têm pra dar".

Aliás, este verso busca se adequar à necessidade de oferecer uma rima compatível com o verso, mais abaixo, "Vai se tornar uma mulher má", já que, em inglês, temos, em posição rimante, os versos "They have some wonderful fun" e "Will grow up to be a bad woman". 


\section{The mother: a mãe}

\section{the mother ${ }^{7}$}

Abortions will not let you forget.

You remember the children you got

[that you did not get,

The damp small pulps with a little or

$$
\text { [with no hair, }
$$

The singers and workers that never

[handled the air.

You will never neglect or beat

Them, or silence or buy with a sweet.

You will never wind up the

[sucking-thumb

Or scuttle off ghosts that come.

You will never leave them, controlling

[your luscious sigh,

Return for a snack of them, with

[gobbling mother-eye

I have heard in the voices of the wind

[the voices of my dim killed children.

I have contracted. I have eased

My dim dears at the breasts they could

[never suck.

I have said, Sweets, if I sinned, if I

[seized

Your luck

And your lives from your unfinished

[reach,

If I stole your births and your names,

Your straight baby tears and your games, Your stilted or lovely loves, your tumults, your deaths,

\section{a mãe}

Os abortos não te deixarão esquecer.

Você se lembra das crianças que teve

[e que não conseguiu ter,

As pequenas polpas, úmidas, com pouco

[cabelo ou nenhum,

Cantores e trabalhadores que jamais

[sentiram a brisa comum.

Você jamais vai bater ou abandoná-las

Ou silenciá-las comprando balas

Você jamais vai vê-las deixar de

[chupar o dedão

Ou fugir dos fantasmas que virão.

Você jamais vai se afastar, para controlar

[seu suspiro de prazer,

E delas fazer lanchinho, com olhos de mãe

[com vontade de morder

Ouço nas vozes do vento as vozes de

[minhas vagas crianças mortas.

De que tenho contrações. Eu aliviei

Minhas queridas indefinidas nos seios que

[jamais puderam mamar.

Tenho dito, doçuras, que, se pequei, se lhes

A sorte pelo azar

[troquei

E lhes tomei a vida de uma chegada bem

[vinda,

Se lhes roubei seus nomes e seus

[nascimentos

Suas brincadeiras, lágrimas e lamentos

Seus amores, amáveis ou forçados, seus

[tumultos, casamentos, dores, e e suas mortes,

7 Originalmente publicado em A Street in Bronzeville (1945). 
If I poisoned the beginnings of your

[breaths,

Believe that even in my deliberateness

II was not deliberate.

Though why should I whine,

Whine that the crime was other

[than mine?

Since anyhow you are dead.

Or rather, or instead,

You were never made.

But that too, I am afraid,

Is faulty: oh, what shall I say, how is the [truth to be said?

You were born, you had body, you died.

It is just that you never giggled or

[planned or cried.

Believe me, I loved you all.

Believe me, I knew you, though faintly, [and I loved, I loved you All.
Se envenenei seus primeiros fôlegos, os

[mais fortes,

Acreditem que, até meu ato mais proposital,

[não foi de propósito.

Mas por que meu lamento só cresceu?

Cresceu pra que eu afirme que esse crime

[não foi meu?

Seja como for, cada um é uma vida extinta

Ou em vez disso, ou ainda,

Nenhum de vocês jamais foi feito.

Mas disso também suspeito,

É imperfeito: ah, o que devo dizer, como se

[deve dizer a verdade sucinta?

Vocês nasceram, vocês tiveram corpo, vocês

[morreram.

Só que vocês nunca sorriram, ou sonharam

[ou sofreram.

Acreditem em mim, eu amei vocês todas.

Acreditem em mim, eu conheci vocês, ainda [que vagamente, e eu amei, amei vocês

Todas.

O poema "the mother" também integra a obra A Street in Bronzeville (1945), permitindo lançar luz sobre os moradores de uma rua de um bairro de Chicago. O poema é particularmente marcante, justamente porque assume o ponto de vista da mãe, expondo os conflitos emocionais decorrentes das suas experiências. $\mathrm{O}$ poema se inicia sugerindo o tema do aborto, no primeiro verso, e no segundo, nos revela uma situação paradoxal: "you remember the children you got that you did not get" (aqui, o tradutor já pode perceber a importância do uso de um mesmo verbo, como em inglês, para expressar esse paradoxo). Até o décimo verso, o poema parece assumir a vOz de uma terceira pessoa, que, de certa forma, vai lembrar a mãe de tudo que o ela não será capaz de testemunhar: a vida de seus filhos/filhas abortados. Essa terceira pessoa tanto pode ser a sociedade recriminando-a, quanto sua própria consciência de mãe lamentando e vivenciando a dor. 
É interessante que, mais adiante, a partir do verso 11, o eu lírico assume, mais claramente, a posição da própria mãe, que busca explicar, o que, para ela, aparentemente, não tem explicação. Ela se ressente de suas escolhas, da morte de seus filhos/filhas, mas, também, é consciente de que suas escolhas, que seus atos "mais propositais" ("my deliberateness") "não foram de propósito" ("was not deliberate”). Aqui podemos observar, de maneira muito sútil, a percepção de que as escolhas dessa mãe não foram puramente suas: foram também imposição das circunstâncias que nós desconhecemos, no contexto do poema, mas que conhecemos muito bem no contexto da vida (especialmente na vida de muitas mulheres negras pobres). Os versos, quiçá, mais complexos do poema, do ponto de vista da tradução, são os seguintes:

- "your deaths"/ "If I poisoned the beginnings of your breaths": sendo a rima um aspecto fundamental do poema, a sua recriação envolve adaptações necessárias no campo semântico, como toda tradução certamente o faz, mas que, podem, porém, ensejar polêmica, já que essas transformações apontam, de maneira mais evidente, o processo de intervenção do tradutor. Nesse caso, a opção de se traduzir "your deaths" por "suas mortes" é, de fato, importante, pois significa que essas crianças não terão a oportunidade de morrer como qualquer pessoa após ter vivido a vida. Nesse caso, foi necessário introduzir uma informação nova, em relação ao texto original, que permitisse a criação da rima com "mortes", nesse caso, em negrito, "seus primeiros fôlegos, os mais fortes." Embora seja uma informação nova, ela contribui para o contexto: toda criança ao nascer é impelida a respirar com os próprios pulmões, sendo essa tomada de fôlego, possivelmente a primeira mais forte que se tem em vida.

- "Since anyhow you are dead" / "Or rather, or instead" [...]"Is faulty: oh, what shall I say, how is the truth to be said": Aqui, também, o problema se refere à recriação de rimas em português que representem as formas em negrito. Os versos correspondentes na tradução são: "Seja como for, cada um é uma vida extinta/ "Ou em vez disso, ou ainda" [...] "É imperfeito: ah, o que devo dizer, como se deve dizer a verdade sucinta". Seria mais natural, talvez, não criar qualquer qualificativo para a verdade, mas a palavra "sucinta" valoriza a imagem da verdade que o eu lírico busca: a verdade mais simples possível (que, porém, paradoxalmente, não se consegue dizer). 
- "Return for a snack of them, with gobbling mother-eye": A complexidade do verso em questão reside na imagem proposta - a de uma mãe absolutamente apaixonada por seu filho/filha. Essa imagem traduz o apego e o carinho exacerbados da mãe, quase sufocantes. Não é sem razão que muitas mães têm vontade de morder o/a filho/filha, de tão "fofinho/a" que ele/ela é. Uma tradução mais próxima de "with gobbling mother-eye" seria "com olhos de mãe de engolir". Recorremos, porém, a uma tradução mais domesticadora, que pudesse fortalecer a imagem, da maneira mais natural possível em português, da mãe que, de modo tão maternal se apodera de sua criança (com uma linguagem carinhosa, inclusive: "delas fazer lanchinho"). Pode-se dizer que a tradução fortalece a dimensão profundamente dolorosa da mãe, do eu-lírico, na medida em que se vale de uma expressão de ternura comumente dita pelas mães: "dá vontade de morder".

- "Though why should I whine" / "Whine that the crime was other than mine?": O verso em questão é de grande complexidade, já que, no plano fonológico, a poeta recorreu a rimas internas e finais no segundo verso em consonância com a palavra final do verso anterior: "whine", que é repetida no início do verso seguinte. Uma tradução mais próxima desses versos, sem a necessária recriação poética, seria: "Porque então devo lamentar?/Lamentar que o crime (do aborto) não foi meu?". A proposta de recriação foi: "Mas por que meu lamento só cresceu?"/"Cresceu pra que eu afirme que esse crime não foi meu?". Na pergunta "Porque devo então lamentar?" (Though why should I whine?), pressupõe-se a ideia de uma dúvida sobre um "dever". Essa dúvida não é mantida na tradução, mas a tradução não deixa de se referir a um questionamento sobre o porquê desse lamento (já que o eu lírico enfatiza que sua ação, no fundo, não foi deliberada, não foi realmente proposital). A tradução busca, assim, reforçar os efeitos sonoros da pergunta, lançando mão de outras semelhanças fonológicas entre as palavras: como "cresceu", "afirme", "crime" e "meu".

\section{Considerações finais}

A tradução de poesia sempre envolverá uma combinação de proximidades e distanciamentos que é, inevitavelmente, oriunda da perspectiva interpretativa particular do tradutor. Nesse sentido, a tradução, sendo um ato de recriação, é a proposta de uma leitura dentre outras possíveis. Nunca será absolutamente objetiva, o que não impede que critérios para uma "objetividade construída", na tradução, possam ser propostos. Sendo construída, essa objetividade não deixa de 
ser atravessada pela subjetividade do tradutor tanto quanto por aquilo que escapa ao seu necessário controle. A objetividade construída é menos a imposição de uma leitura que expresse uma verdade única (o que, felizmente, é impossível), do que o desejo de se oferecer uma leitura tão aceitável quanto desejável do Outro (aqui, o desejo e a aceitabilidade se mesclam). Traduzir é esse gesto dramático de alegria em se ouvir o Outro, um Outroeu.

\section{Referências bibliográficas}

BROOKS, G. A Street in Bronzeville. New York, N. Y.: Harpers and Brothers, 1945. . The Bean Eaters. New York, N. Y.: Harpers and Brothers, 1960.

GATES, H. L.; McKAY, N. Y. (Orgs.). The Norton Anthology of African American Literature. 2nd. Edition. New York, London: Norton \& Company, 2004. 